\title{
Analysis of Stakeholders towards E-Sap-An ICT Tool for Pest Management-An Empirical Study
}

\author{
G.N. Maraddi ${ }^{1 *}$, A. Prabhuraj ${ }^{2}$ and G.M. Hiremath ${ }^{3}$ \\ ${ }^{1}$ Krishi Vigyan Kendra, Gangavathi, UAS, Raichur, India \\ ${ }^{2}$ Entomology, ${ }^{3}$ Agricultural Economics, AC, Raichur, University of Agricultural Sciences, \\ Raichur-584 102, Karnataka, India \\ *Corresponding author
}

\begin{tabular}{|l|}
\hline K e y w o r d s \\
e-SAP, Perception, \\
Field facilitator, \\
Farmers and \\
Relationship with \\
SES status \\
\hline Article Info \\
\hline Accepted: \\
12 March 2019 \\
Available Online: \\
10 April 2019 \\
\hline
\end{tabular}

\begin{abstract}
A B S T R A C T
\end{abstract}
The research study was conducted in northeastern region of Karnataka (NEK) to assess the perception of the stake holders of e-SAP dissemination tool. The ex-post-facto research design was used for the study with 384 stakeholders. e-SAP is an important ICT flat form, which facilitates the access of relevant, technical feasible, economically affordable with socially acceptable information to the decision making system of various stakeholders in agriculture field. e-SAP refers to electronic solutions against agriculture pest. It enables the rapid \& effective dissemination of need based and fruitful technologies to farm lands and delivery of farm data in various farms to different stake holders like Farmers, Extension officers, Researchers, Policy makers and other users. This technology is successfully designed, tested \& adopted by University of Agricultural Sciences Raichur in association with Tene Agriculture solutions private limited, Bangalore. e-SAP plays pivotal role in minimization of crop losses due to incidence of pest. About half of the $(45.95 \%)$ the field facilitator belongs to high perception category, whereas nearly equal percentage of the farmers were shared and identified in medium to high category (36.98\% and $32.55 \%$ ). The statement-wise perception analysis is skewed towards higher side for both field facilitator and farmers. The correlation analyses revealed that, age and education of the farmers had shown negative and significant relationship with their perception towards esap at $1 \%$ level of probability in management of pest. It seems age old farmers and long experienced farmers had negative perception towards e-sap. Education, Risk orientation and Information management had shown positive and significant relationship with their perception towards e-SAP at $1 \%$ level of probability, whereas Management orientation has shown positive and significant relationship with their perception towards e-SAP at 5\% level of probability.

\section{Introduction}

e-SAP is one of the important emerging and efficient dissemination tool for agricultural pest management. e-SAP refers to electronic solution for agricultural pest management. eSAP is a ground - breaking application built on the backdrop of agricultural pest management. It foundation lies on a unique platform that facilitates the storage access and 
transfer information between all stake holders in agriculture. It enables rapid and delivery of farm data in various forms including multimedia to researchers, policymakers and other users in real time. e-sap has been successfully built and tested and deployed by UAS Raichur in association with Tene agriculture solution pvt. ltd, Bangalore. eSAP is novel ICT platform and dedicated field device capable of making two way information exchange in real time is available today. With huge potential for revolutionizing transfer of technology system, it has opened doorway for the future particularly in India and world in general. The potential is such that any new agricultural technology can be communicated in an extremely effective manner in real time directly to the field, for instance, if new pest management strategy has to be disseminated to many field workers spread across a vast geography, a press the button in the computer lab all it takes to deliver it instantaneously to all of them, such information can be assessed anytime, anywhere, irrespective of connectivity. Simultaneously, field situations across the space and time are instantaneously made known to the decision maker.

\section{Materials and Methods}

The research study was conducted in northeastern region of Karnataka (NEK) to assess the perception of the stake holders of eSAP dissemination tool. The ex-post-facto research design was used for the study with 384 stakeholders. The random sampling procedure is being used in six northeastern districts to draw optimum sample size for the study. A scale was developed to measure the perception of respondents by following the standard procedure for both farmers and field facilitator. Around ten independent variables in addition to one dependent variable is being used for the research study. The standardized schedule used to investigate the information from the stakeholders of e-SAP. Sphersmans simple correlation test was used to know the relationship between selected variables.

\section{Results and Discussion}

\section{Overall perception of farmers towards e- sap in NEK region}

It was observed from the Table 1 that, overall perception of farmers towards e-sap. The trend is relatively more members of farmers belongs to high category in Raichur, Yadagir, Bellary and others except Gulbarga which has equal number in all categories of perception. Totally around 37 percent $(36.98 \%)$ of the respondents belongs to medium perception $(32.55 \%)$ and only 30.47 percent of the respondents belong to low perception category. The results are in line with the results obtained by Sankri (2013), who has conducted a study on perception of the extension officials towards TNAU agritech portal and reported that more than half (61.67 $\%$ ) of the respondents have medium level of perception followed by nearly one forth $(23.33 \%)$ of the respondents in low perception category. Similar results were also reported by Hayrol and Bahaman (2009) where in Overall, ICT were perceived moderate to high in terms of their importance for the development of their village among the village development committee members.

\section{Statement-wise mean perception score of farmers towards e-sap in NEK region}

A cursory look at the Table 2 indicated that, statement of perception men score about e-sap in NEK region, that it makes pest disease identification and diagnosis easier, timely information injudicious use of pesticides by farmers, provides opportunities for interaction with experts, reduces the cost of pest and diseases management through relevant solution with the mean score of 2.48 . Whereas 
e-sap is credible in nature, easy to understand and adopt, increase yield raised with the mean score less than above mentioned statements. It seems maximum score 3 , out of three, more than two shows the favourable perception towards e-sap. An outset, majority stands are being used to the inputs and got encouraging results.

\section{Personal, socio-economic and psychological characteristics of the respondents}

From Table 3, it could be inferred that in total nearly half $(48.70 \%)$ of the respondents belonged to be middle age category followed by young $(35.94 \%)$ and old $(15.36 \%)$ aged categories. The probable reasons for majority of the respondents to be in middle age category might be that, usually farmers of middle age are enthusiastic and having moderate experience in farming have more work efficiency than older and younger ones. The results are in conformity with the findings of Suresh (2004). It is evident from the Table 3, one third $(30.99 \%)$ of the respondents were illiterates. 24.48 per cent of them were educated up to high school followed by middle school $(17.45 \%)$ and PUC (13.54\%). The probable reasons for the majority of respondents to be illiterates might be poorer economic condition, non realization of importance of formal education and also ignorance and non availability of educational facilities at village level. As per the results of Table 3, majority (38.54 \%) of the respondents were medium farmers. Nearly one third $(30.21 \%)$ of them were small farmers followed by big $(25.52 \%)$ and marginal $(5.73 \%)$ farmers category. The probable reasons may be transfer of ancestral lands from generation to generation. It was observed from the Table 3 that, majority $(45.31 \%)$ of the respondents were in high income group and 27.86 per cent of them were in low income group followed by medium (14.06 \%) and semi medium (12.76
$\%)$ income categories respectively. The probable reasons, which could be attributed for varied income level of the respondents, might be due to the size of land holding, price fluctuations in the market and practicing other occupations. With regards to farming experience, 41.41 per cent of the respondents belonged to low farming experience category followed by medium (33.85\%) and high $(24.74 \%)$ farming experience categories respectively. The above results could not be attributed to the fact that majority of the respondents were middle aged with medium land holdings. The above findings are in line with the findings of Vijaykumar and Narayanagowda (1999). It was observed from the Table 3 that, majority $(45.57 \%)$ of the respondents had medium achievement motivation followed by high $(28.13 \%)$ and low (26.30 \%) achievement motivation. Achievement motivation is a psychological variable. It differs from individual to individual. It is assumed that achievement motivation forces the individual towards reaching some goals, which he set for himself. Higher the association with the individual higher will be his efforts. This can be attributed to the social status of a respondent feels to keep by achieving greater goals. The findings are the in accordance with the studies conducted by Vijaykumar (2001) and Nagesh (2005). With regard to risk orientation it was observed from Table 3 that, majority of the respondents $(43.23 \%)$ had medium risk orientation followed by high $(29.17 \%)$ and low $(27.60 \%)$ risk orientation respectively. It depends up on personal, psychological and socio-economic characteristics. The individual with more experience have a better risk taking ability. All these are the possible reasons because of which majority of them possess medium risk orientation. It was observed from the Table 3 that, majority $(44.53 \%)$ of the respondents belonged to medium management orientation followed by low $(28.91 \%)$ and high (26.56 \%) 
management orientation category respectively. The probable reasons might be due medium level of achievement motivation and risk taking ability of the respondents. It was observed from the Table 3 that, majority (47.14 \%) of the respondents belonged to medium innovative proneness category followed by low (27.08 \%) and high (25.78 $\%)$ categories respectively. The medium innovativeness of the respondents might be due to their marginal size of the land holding and majority were middle aged which had restricted them to go always for new things. Apart from this their low level of the extension contact, medium level of extension participation contributed to their medium level of innovativeness. Similar results were also reported by Nagesh et al., (2011). It was observed from the Table 3 that, majority $(46.88 \%)$ of the respondents belonged to medium level of information management followed by high (28.39\%) and low (24.74 $\%$ ) information management categories respectively.

\section{Overall perception of farm facilitator towards e-SAP in NEK region}

It was observed from the Table 4 that, overall perception of Farm Facilitator towards e-sap in NEK region of Karnataka state. About half of Farm Facilitator belongs to high perception (>45.95 - range interval) category followed by low perception category $(31.58 \%)$ with range of <42.04 and only 21.05 percent of Farm Facilitator were identified in medium category, range interval of 42.04 to 45.59 . This trend is due to rapid and speed availability of information, accuracy in synthesis with multimedia data capturing capacity in addition to web based application, which ensures the data generation from field to disseminate through field devices back to the respondents. Further it will support decision support system of stake holders in agriculture system. The results are in line with the results obtained by Sankri (2013), who has conducted a study on perception of the extension officials towards TNAU agritech portal and reported that more than half $(61.67$ $\%$ ) of the respondents have medium level of perception followed by nearly one forth $(23.33 \%)$ of the respondents in low perception category.

Statement-wise mean perception score of farm facilitator towards e-SAP in NEK region

A access look at Table 5 that statement wise perception score of farm facilitator revealed that, usage of e-sap helps the farmers to reduce the cost of pest management with the mean score of 2.63 followed by access any information regarding pest and disease management at any time and any where, and e-sap helps in identification of pest in addition timely decisions with regard to pest management with the mean score of 2.63 followed by e-sap influences farmers to adopt, latest pest and disease management practices, provides opportunity to farmers for interaction with experts and it is easy to complete work in short time in addition to it act as ready reckanor for advising farmers with the mean score of 2.53. Whereas immediate solution to the identified pest (2.00), latest information of pest management, in addition e-sap helps in effective and efficient job performance (mean score of 2.47).

The results gets partial support from the results obtained by Singh et al., (2012) in their study reviled that majority of the efarmers $(91.82 \%)$ perceived it as a better source of timely and quick information, followed by source of strong linkage with KVK (81.23 \%), need based information $(77.13 \%)$, easy to understand the message $(77.00 \%)$. 
Zero order correlation between independent variables farmers with their perception level

It was observed from the Table 6 that, age and farming experiences of the farmers had shown negative and significant relationship with their perception level at 1 percent level of probability. It seems as age and farming experiences increases the corresponding by favorable perception decreases towards e-sap dissemination tools. Since it requires exposure to recent ICTs tools, to use of tablet to get timely and relevant information, which is lacking among older people, hence age and farming experiences negatively significant with perception level of farmers. Whereas education of the farmers had shown positive and significant relationship with their perception towards e-sap tool. As education widen the mental horizon of the individual, which helps empowerment of grasping capacity of recent ICT tool in excess of information. So use of tablet and utilization of e-sap is more significant.

Table.1 Overall perception of farmers towards e-sap

\begin{tabular}{|c|c|c|c|c|c|c|}
\hline \multirow{2}{*}{ Categories } & \multicolumn{2}{|c|}{ Low Perception } & \multicolumn{2}{c|}{ Medium Perception } & \multicolumn{2}{c|}{ High Perception } \\
\cline { 2 - 6 } & Freq. & \% & Freq. & $\%$ & Freq. & \% \\
\hline Raichur & 36 & 37.11 & 10 & 10.31 & 51 & 52.58 \\
\hline Gulbarga & 42 & 33.33 & 42 & 33.33 & 42 & 33.33 \\
\hline Yadgir & 30 & 36.59 & 13 & 15.85 & 39 & 47.56 \\
\hline Bellary and & 25 & 31.65 & 22 & 27.85 & 32 & 40.51 \\
\hline Total & 117 & 30.47 & 142 & 36.98 & 125 & 32.55 \\
\hline
\end{tabular}

Table.2 Statement wise perception mean score farmers about e-sap

\begin{tabular}{|c|l|c|c|c|c|c|}
\hline Sl. & \multicolumn{5}{|c|}{ Statements } & \multicolumn{5}{c|}{ Mean score } \\
\cline { 4 - 7 } No & & Raichur & Gulbarga & Yadgir & Bellary & Total \\
\hline $\mathbf{1}$ & e-sap makes the pest and disease identification & 2.29 & 2.59 & 2.77 & 2.75 & 2.58 \\
\hline $\mathbf{2}$ & e-sap provides latest and updated information in & 2.04 & 2.50 & 2.00 & 2.39 & 2.26 \\
\hline $\mathbf{3}$ & When new pest or disease is observed it is & 1.93 & 2.14 & 1.66 & 2.03 & 1.96 \\
\hline $\mathbf{4}$ & e-sap provides timely information for the pest or & 2.28 & 2.56 & 2.68 & 2.59 & 2.52 \\
\hline $\mathbf{5}$ & e-sap provides reliable and specific information & 2.41 & 2.32 & 2.59 & 2.57 & 2.45 \\
\hline $\mathbf{6}$ & e-sap is user friendly as it contains multimedia & 2.23 & 2.26 & 2.61 & 2.63 & 2.40 \\
\hline $\mathbf{7}$ & e-sap reduces the injudicious use of pesticides by & 2.27 & 2.73 & 2.50 & 2.52 & 2.52 \\
\hline $\mathbf{8}$ & e-sap provides opportunities for interaction with & 2.33 & 2.32 & 2.62 & 2.72 & 2.47 \\
\hline $\mathbf{9}$ & e-sap provides opportunity for expressing & 1.90 & 2.29 & 2.22 & 2.52 & 2.22 \\
\hline $\mathbf{1 0}$ & e-sap provides information in local language and & 2.34 & 2.48 & 2.59 & 2.67 & 2.51 \\
\hline $\mathbf{1 1}$ & It reduces the cost of pest and disease & 2.22 & 2.60 & 2.51 & 2.58 & 2.48 \\
\hline $\mathbf{1 2}$ & e-sap enhances the rapid dissemination of pest & 2.31 & 2.40 & 2.70 & 2.63 & 2.49 \\
\hline $\mathbf{1 3}$ & Information available from e-sap is credible in & 2.08 & 2.29 & 2.48 & 2.41 & 2.30 \\
\hline $\mathbf{1 4}$ & Information on pest and disease can be accessed & 2.26 & 2.33 & 2.59 & 2.67 & 2.43 \\
\hline $\mathbf{1 5}$ & e-sap should be extended to all parts of the state & 2.16 & 2.35 & 2.66 & 2.67 & 2.43 \\
\hline $\mathbf{1 6}$ & e-sap helps in increasing the yield level of & 2.13 & 2.58 & 2.41 & 2.43 & 2.40 \\
\hline $\mathbf{1 7}$ & e-sap helps to reduce the extent of damage by & 2.22 & 2.59 & 2.59 & 2.65 & 2.51 \\
\hline
\end{tabular}


Table.3 Personal, socio-economic and psychological characteristics of the farmers

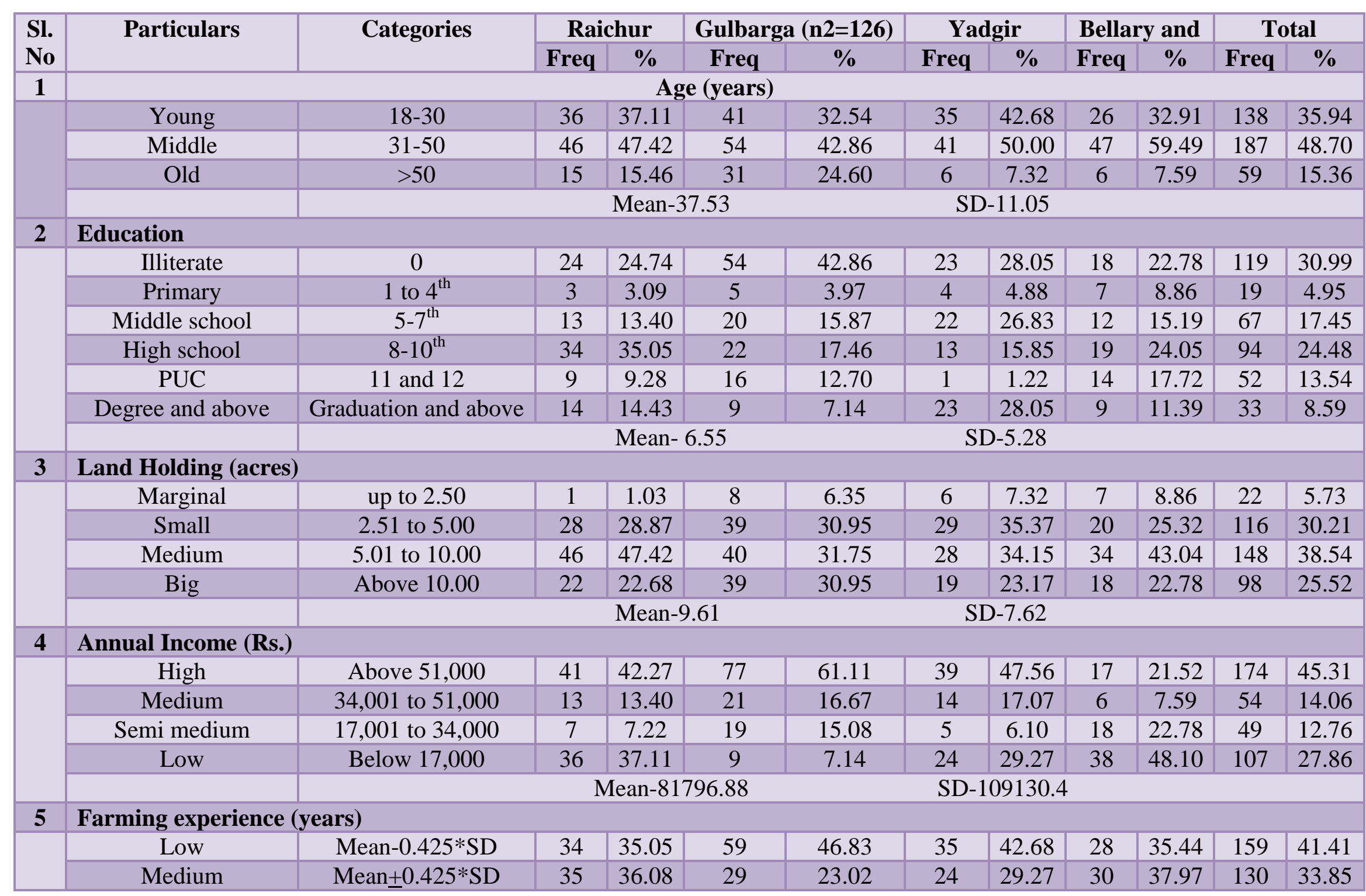




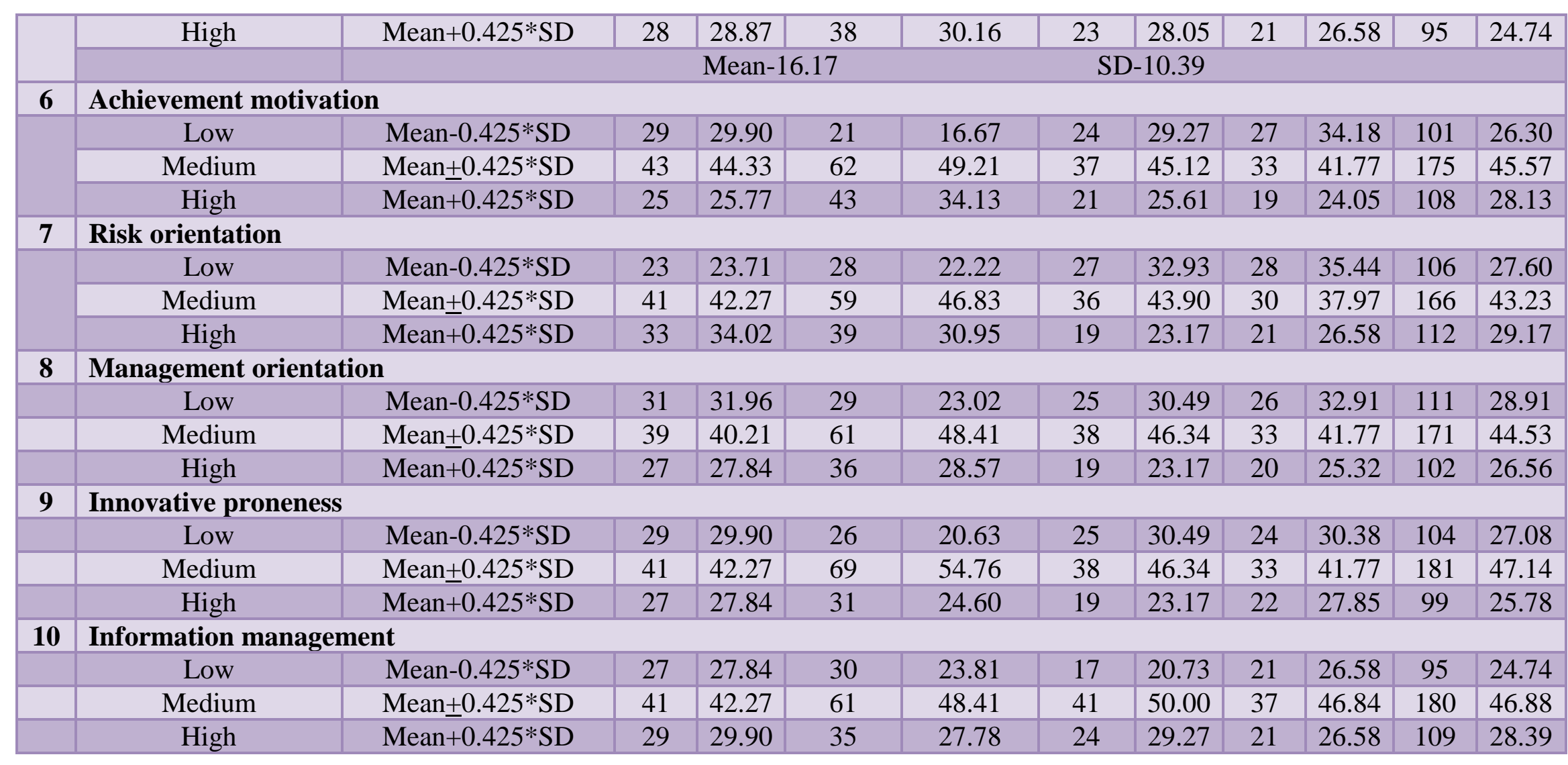

Table.4 Overall perception of farm facilitators towards e-sap (n-18)

\begin{tabular}{|c|c|c|c|}
\hline Sl. No. & Categories & Frequency & Percentage \\
\hline $\mathbf{1}$ & Low & 6 & 31.58 \\
\hline $\mathbf{2}$ & Medium & 4 & 21.05 \\
\hline $\mathbf{3}$ & High & 9 & 47.37 \\
\hline
\end{tabular}


Table.5 Statement wise perception mean score of farm facilitators about e-sap (n-18)

\begin{tabular}{|c|l|c|}
\hline Sl. & \multicolumn{1}{|c|}{ Statements } & Mean \\
\hline $\mathbf{1}$ & e-sap influences the farmers to adopt latest pest and disease management & 2.53 \\
\hline $\mathbf{2}$ & Using the e-sap helps the farmers to reduce the cost of pest management & 2.63 \\
\hline $\mathbf{3}$ & e-sap improves the productivity of various crops & 2.37 \\
\hline $\mathbf{4}$ & Operating e-sap device is difficult & 1.47 \\
\hline $\mathbf{5}$ & It takes lot of time to get information on particular pest or disease & 2.47 \\
\hline $\mathbf{6}$ & e-sap provides latest information on pest management to the farmers & 2.32 \\
\hline $\mathbf{7}$ & e-sap provides opportunity to farmers for interaction with experts & 2.53 \\
\hline $\mathbf{8}$ & Farmers can access any information regarding pest and disease management & 2.63 \\
\hline $\mathbf{9}$ & e-sap provides information on pest and diseases and their management only & 2.63 \\
\hline $\mathbf{1 0}$ & e-sap helps in rapid dissemination of latest technologies in pest management & 2.42 \\
\hline $\mathbf{1 1}$ & e-sap helps in easy identification of pests & 2.63 \\
\hline $\mathbf{1 2}$ & e-sap helps the farmers in making timely decisions regarding pest & 2.63 \\
\hline $\mathbf{1 3}$ & e-sap provides immediate solutions to the identified pests & 2.00 \\
\hline $\mathbf{1 4}$ & e-sap provides information in local language which is clearly understandable & 2.58 \\
\hline $\mathbf{1 5}$ & High skills and knowledge is required to operate e-sap device & 2.63 \\
\hline $\mathbf{1 6}$ & It makes easy to complete a work in short time & 2.53 \\
\hline $\mathbf{1 7}$ & It act as ready reckonor for advising farmers & 2.53 \\
\hline $\mathbf{1 8}$ & It helps in effective and efficient job performance & 2.47 \\
\hline
\end{tabular}

Table.6 Correlation between selected independent variables and perception (n-384)

\begin{tabular}{|c|l|c|}
\hline SI. No. & \multicolumn{1}{|c|}{ Variables } & Correlation \\
\hline $\mathbf{1 .}$ & Age & $-0.341^{* *}$ \\
\hline $\mathbf{2 .}$ & Education & $0.260^{* *}$ \\
\hline $\mathbf{3 .}$ & Land Holding & 0.054 \\
\hline $\mathbf{4 .}$ & Farming experience & $-0.279^{* *}$ \\
\hline $\mathbf{5 .}$ & Annual Income & 0.049 \\
\hline $\mathbf{6 .}$ & Achievement motivation & 0.21 \\
\hline $\mathbf{7 .}$ & Risk orientation & $0.47^{* *}$ \\
\hline $\mathbf{8 .}$ & Management orientation & $0.56^{*}$ \\
\hline $\mathbf{9 .}$ & Innovative proneness & 0.19 \\
\hline $\mathbf{1 0 .}$ & Information management & $0.59^{* *}$ \\
\hline
\end{tabular}

Hence the education of respondents had significant relationship with perception level towards e-sap. Hayrol and Bahaman (2009) reported that factor of age found to have negative and weak relationship with perception towards the importance of ICT.

In conclusion, e-SAP is a novel ICT tool which enables the rapid and delivery of farm data in various forms including multimedia to researchers, policymakers and other users in real time. e-sap has been successfully built and tested and deployed by UAS Raichur in association with Tene agriculture solution pvt.ltd, Bangalore. e-SAP is ICT platform and dedicated field device capable of making two way information exchange in real time is available today. With huge potential for 
revolutionizing transfer of technology system, it has opened doorway for the future course of action particularly in India and world in general. Perception analyses of stake holders had skewed towards higher side. It shows that wider potentiality for application at farmers' field level. In addition it empowers field facilitator to diagnose the pest incidence, disease incidence, Physiological disorder, weeds as well as scientific advising to ensure timely decision making system of farmers. Intern this will helps in management pest, disease, disorder in least cost, there by increases the marginal return of crop enterprises.

\section{References}

Hayrol, A. M. S. and Bahaman A. S., 2009, Perception towards importance of information and communication technology among rural administrators. Journal of Agriculture and Social Sciences, 5: 67-72.

Nagesh, 2005, Study on entrepreneurial behaviour of vegetable seed producing farmers in Haveri district of Karnataka. M. Sc. (Agri.) Thesis, University of Agricultural Sciences, Dharwad.

Nagesh, B., Halakatti, S.V. and Hanchinal, S.N., 2011, Study on entrepreneurial behaviour of pomegranate growers. Agriculture Update. Vol. 6 (3\&4):122-125.
Sankri, S. K., Anand R, N., and shibi S., 2013, Perception of the extension officials towards TNAU agritech portal. In: proceedings of international conference on extension educational strategies for sustainable agricultural development-a global perspective. University of agricultural sciences, Bangalore, India. Pp 220-221.

Singh, S. K., Gautam, U. S., Anupam, M., and Tushar, A., 2012, In: proceedings of international conference on extension educational strategies for sustainable agricultural development-a global perspective. University of agricultural sciences, Bangalore, India. Pp 220221.

Suresh, 2004, Entrepreneurial behaviour of milk producers in Chittoor district of Andhra Pradesh - A critical study. M. V. Sc. Thesis, Acharya N. G. Ranga Agricultural University, Hyderabad.

Vijay Kumar, K., 2001, Entrepreneurship behaviour of floriculture farmers in Ranga Reddy district of Andhra Pradesh. M. Sc. (Agri.) Thesis, Acharya N. G. Ranga Agricultural University, Hyderabad.

Vijaykumar, A. C., and Narayanagowda, K., 1999, Adoption of improved cultivation practices among Rose growers. Journal of Extension Education, 10: 2331 - 2334.

\section{How to cite this article:}

Maraddi, G.N., A. Prabhuraj and Hiremath, G.M. 2019. Analysis of Stakeholders towards ESap-An ICT Tool for Pest Management - Empirical Study. Int.J.Curr.Microbiol.App.Sci. 8(04): 1489-1497. doi: https://doi.org/10.20546/ijcmas.2019.804.174 